\title{
RESISTÊNCIA DO CONCRETO CURADO EM BAIXA TEMPERATURA
}

\section{Compressive strength of concrete cured at low temperature}

\author{
Gabriel Ronsoni Woinarski TEIXEIRA ${ }^{1}$; Lucas Boabaid IBRAHIM ${ }^{2}$; \\ Carlos Eduardo Tino BALESTRA ${ }^{3}$; Gustavo SAVARIS ${ }^{4}$
}

Recebido em 16 de fevereiro de 2019; aceito em 08 de setembro de 2020; disponível on-line em 11 de maio de 2020.

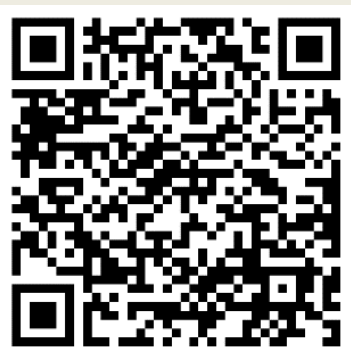

PALAVRAS CHAVE:

Concreto;

Cura;

Resistência à compressão;

Temperatura;

Concretagem.

\section{KEYWORDS:}

Concrete;

Curing;

Compressive strength;

Temperature;

Concreting.

RESUMO: Os eventos climáticos não podem ser evitados e seus efeitos sobre as edificações afetam sua vida útil. Na região sul do Brasil temperaturas inferiores a $10^{\circ} \mathrm{C}$ durante grande parte do inverno, dificultam, ou até inviabilizam a realização de concretagens. No presente trabalho corpos de prova cilíndricos de concreto foram submetidos ao processo de cura em água a temperatura ambiente $\left(23 \pm 2{ }^{\circ} \mathrm{C}\right)$ de laboratório e em temperatura próxima ao congelamento $\left(5^{\circ} \mathrm{C}\right)$, ambos com umidade relativa mínima de $95 \%$, durante 3,7 e 28 dias, sendo a resistência à compressão determinada nestas idades a fim de avaliar a influência da temperatura durante o processo de cura na evolução da resistência do concreto quando submetidos à baixa temperatura. Os resultados demonstraram que a temperatura é capaz de retardar as reações de hidratação do cimento com consequências ao processo de desenvolvimento da resistência à compressão do concreto, principalmente nas primeiras idades. Entretanto, concretos submetidos à baixa temperatura nos primeiros sete dias e transferidos para temperatura ambiente até os 28 dias apresentaram aumento de resistência, aproximando-se de valores de resistência de corpos de prova curados aos 28 dias em temperatura ambiente. Os resultados comprovam que a concretagem em temperaturas até $5^{\circ} \mathrm{C}$ podem ser realizadas, desde que sejam tomados cuidados quanto à idade de retirada das escoras, contribuindo na melhoria dos processos construtivos.

ABSTRACT: Climatic events cannot be avoided and their effects on buildings affect their lifetime. In the southern region of Brazil temperatures below $10{ }^{\circ} \mathrm{C}$ during the winter make difficult or even impossible the concreting process. In the present paper, cylindrical concrete specimens were cured in water at ambient temperature $\left(23 \pm 2{ }^{\circ} \mathrm{C}\right)$ and at refrigerated temperature $\left(5^{\circ} \mathrm{C}\right)$, both with a minimum relative humidity of $95 \%$ during 3 , 7 and 28 days, and the compressive strength was determined at these ages in order to evaluate the influence of the temperature during the curing process on the evolution of the concrete resistance when subjected to low temperature. The results demonstrated that the temperature is able to retard the hydration reactions of the cement with consequences to the process of development of the compressive strength of the concrete, especially at early ages. However, concrete submitted to low temperature in the first seven days and transferred to ambient temperature until 28 days presented increased resistance, approaching to resistance values of specimens cured at 28 days at ambient temperature. The results confirm that concreting at temperatures up to $5{ }^{\circ} \mathrm{C}$ can be carried out, since care is taken regarding the age of withdrawal the posts that support the structure, contributing to the improvement of the constructive process.

\footnotetext{
* Contato com o autor:

${ }^{1}$ e-mail: gabriel.rwt@hotmail.com (G. R.W. Teixeira )

Bacharel em Engenharia Civil, Universidade Tecnológica Federal do Paraná.

${ }^{2}$ e-mail:ibrahim@utfpr.edu.br ( L. B. Ibrahim )

Engenheiro Civil, Doutor em Engenharia Civil, Professor Adjunto, Universidade Tecnológica Federal do Paraná.

${ }^{3}$ e-mail: carlosbalestra@utfpr.edu.br (C. E. T. Balestra)

Engenheiro Civil, Doutor em Infraestrutura Aeronáutica, Professor Adjunto, Universidade Tecnológica Federal do Paraná.

${ }^{4}$ e-mail: gsavaris@utfpr.edu.br (G. Savaris )

Engenheiro Civil, Doutor em Engenharia Civil, Professor Adjunto, Universidade Tecnológica Federal do Paraná.
} 


\section{INTRODUÇÃO}

Devido a sua grande extensão territorial, observa-se uma diversificação climática no Brasil, sendo que o clima na Região Sul apresenta chuvas bem distribuídas no decorrer do ano com estações notadamente distintas (OLIVEIRA, 2003). Neste clima, o inverno é rigoroso, com grandes quedas de temperatura acompanhadas por geadas, e até mesmo a ocorrência de neve em regiões mais altas. Durante o inverno, a temperatura mínima média se mantém consideravelmente baixa, variando entre 6 e $12{ }^{\circ} \mathrm{C}$, sendo que temperaturas próximas a $0{ }^{\circ} \mathrm{C}$ ou até mesmo negativas são facilmente registradas (NERY, 2005). A Figura 1 apresenta as temperaturas médias ocorridas durante o ano de 2016, onde se verifica que para grande parte da região sul a temperatura média ficou abaixo de $20^{\circ} \mathrm{C}$, havendo locais em que a temperatura média foi próxima de $12{ }^{\circ} \mathrm{C}$.

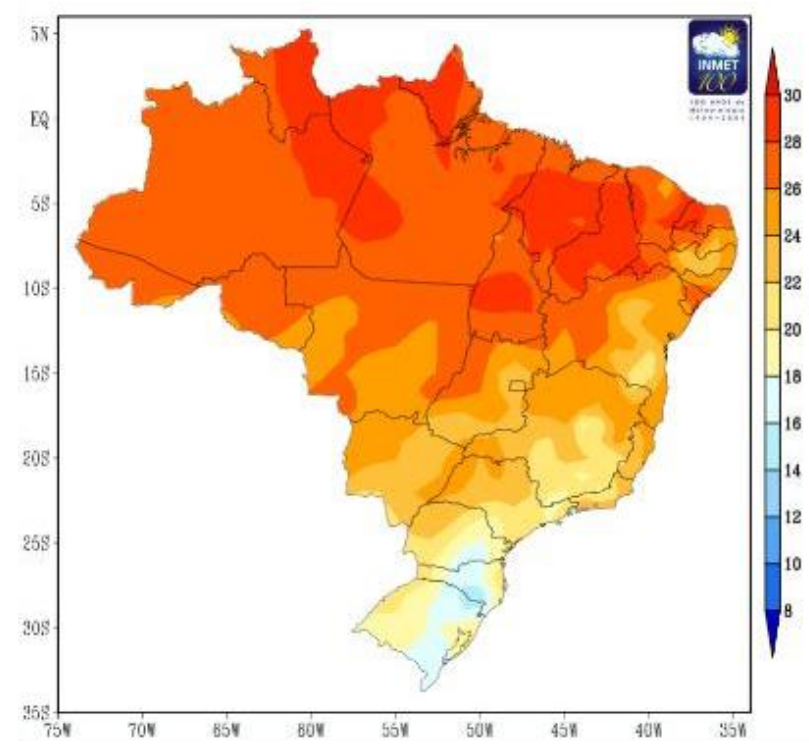

FIGURA 1: Temperaturas médias observadas em 2016 Fonte: INMET, 2017.

Segundo a norma NBR 14931 (ABNT, 2004), a temperatura da massa de concreto, no momento do lançamento, não deve ser inferior a 5 ${ }^{\circ} \mathrm{C}$. Esta também recomenda que a concretagem seja suspensa sempre que estiver prevista queda na temperatura ambiente para abaixo de $0{ }^{\circ} \mathrm{C}$ nas $48 \mathrm{~h}$ seguintes. Concretos com relação água cimento abaixo de 0,6 quando expostos a baixas temperaturas nas primeiras 24 horas após a mistura dos materiais apresentam significativa redução na resistência à compressão (KOSMATKA et al., 2003).

Reginato, Foiato e Piovesan (2013) destacam que a baixa temperatura durante 0 processo de cura do concreto pode delongar e, até mesmo impedir, o desenvolvimento de reações que garantem sua resistência. Nessas condições, as reações de hidratação podem ocorrer lentamente, retardando a pega e o endurecimento do concreto, ou nem mesmo ocorrer, devido à falta de água.

Os problemas de hidratação, provocados pela ineficiência do processo de cura, podem trazer consequências irreversíveis ao concreto. Em temperaturas abaixo de $5{ }^{\circ} \mathrm{C}$ a água presente no concreto congela, impedindo a hidratação do cimento e reduzindo o desenvolvimento de resistência do concreto. Além disso, a expansão de volume da água durante o congelamento pode reduzir a resistência final do concreto (KRYLOV, 1999).

Visto que durante 0 inverno $o$ retardamento da pega do concreto pode ocorrer facilmente devido às baixas temperaturas, e este retardamento pode causar uma redução nas resistências em idades iniciais e até mesmo impossibilitar a desforma de peças estruturais. Em condições de clima frio, Ortiz et al. (2005) recomendam que a concretagem ocorra nas primeiras horas do dia, de forma que coincida o aumento temperatura durante $\mathrm{o}$ dia com $\mathrm{o}$ endurecimento do concreto.

Considerando que as propriedades do concreto podem ser afetadas pela temperatura dos materiais constituintes ou do ambiente, durante as fases de produção e cura, este trabalho se justifica pela necessidade de conhecer como o concreto se comporta diante de baixas temperaturas.

\subsection{OBJETIVO}

O objetivo desta pesquisa consistiu em avaliar a influência da exposição do concreto à baixa temperatura durante o período de cura em sua resistência à compressão uniaxial, realizando um programa experimental com corpos de prova submetidos à cura imersos em água em temperaturas iguais a $5^{\circ} \mathrm{Ce} 23^{\circ} \mathrm{C}$, durante períodos 
entre 3 e 28 dias e também com alternância entre as condições de cura.

\section{RESISTÊNCIA DO CONCRETO EM CONDIÇÕES DE BAIXA TEMPERATURA}

O desenvolvimento da resistência do concreto é influenciado por ações químicas internas e pelas condições do ambiente externo, principalmente a temperatura. Segundo Mehta e Monteiro (2008), a resistência do concreto pode ser afetada pela temperatura do lançamento do concreto e pela temperatura de cura.

Reginato, Foiato e Piovesan (2013) constataram experimentalmente que a resistência à compressão é afetada negativamente com a redução da temperatura de cura do concreto, resultando na redução de até $35 \%$ da resistência à compressão do concreto quando curado a $8{ }^{\circ} \mathrm{C} \mathrm{em}$ comparação com a cura a $23^{\circ} \mathrm{C}$, aos 28 dias.

Resultados semelhantes foram obtidos por Lansini (2016) em corpos de prova submetidos à cura em banho térmico a $5^{\circ} \mathrm{C}$ e $25^{\circ} \mathrm{C}$. Enquanto o concreto curado em temperaturas baixas não atingiu a resistência pretendida de $40 \mathrm{MPa}$, tanto para primeiras idades, quanto para 28 dias, na temperatura de cura de $25^{\circ} \mathrm{C}$ ocorreu um crescimento gradual de resistência à compressão, ultrapassando os $40 \mathrm{MPa}$ aos 28 dias.

Em ensaios com concretos curados em temperaturas próximas ao congelamento, Nassif e Petrou (2013) verificaram uma redução de $20 \%$ e $25 \%$ no módulo de elasticidade e na resistência à compressão, respectivamente, em relação aos concretos curados em temperatura acima de $20^{\circ} \mathrm{C}$.

Entretanto, Cecconello e Tutikian (2012) verificaram que quando o concreto é submetido à cura em temperaturas entre 0 e $25^{\circ} \mathrm{C}$ durante os primeiros 7 dias de idade e então transferido para cura em temperatura a $20^{\circ} \mathrm{C}$ ocorre um aumento de resistência em relação ao concreto curado somente em temperatura próximo de $20^{\circ} \mathrm{C}$, sendo este efeito atribuído à hidratação mais lenta do cimento, ocasionando uma melhor formação da estrutura cristalina.

\section{MATERIAIS E PROGRAMA EXPERIMENTAL}

O aglomerante utilizado para produção do concreto foi Cimento Portland Tipo II F-32. O agregado miúdo empregado foi areia natural proveniente do rio Paraná, com massa específica igual a $2,56 \mathrm{~g} / \mathrm{cm}^{3}$ e módulo de finura igual a $1,74, \mathrm{e}$, como agregado graúdo, rocha britada de origem basáltica com massa específica igual a $2,88 \mathrm{~g} / \mathrm{cm}^{3} \mathrm{e}$ dimensão máxima característica igual a $19 \mathrm{~mm}$.

As proporções de materiais da mistura de concreto são apresentadas na Tabela 1. A relação água cimento da mistura foi definida como 0,43 , com um consumo de cimento de aproximadamente $476 \mathrm{~kg} / \mathrm{m}^{3}$ de concreto. Os materiais foram misturados em uma betoneira com capacidade de produção de 80 litros por betonada. Após a mistura foi realizado o ensaio para determinação da consistência pelo abatimento do tronco de cone (ABNT NBR NM 67/1998), que resultou em 9,5 cm, sendo, em seguida, moldados os corpos de prova cilíndricos, com $10 \mathrm{~cm}$ de diâmetro e $20 \mathrm{~cm}$ de altura, seguindo as recomendações da norma NBR 5738 (ABNT, 2015).

Após 24 horas os corpos de prova foram desmoldados e submetidos à cura submersos em água com cal, em duas condições de temperatura da água: $23 \pm 2^{\circ} \mathrm{C}$ ou cura em local refrigerado a $5^{\circ} \mathrm{C}$.

TABELA 1: Consumo de materiais para produção do concreto.

\begin{tabular}{cccc} 
Cimento $\left(\mathrm{kg} / \mathrm{m}^{3}\right)$ & Areia $\left(\mathrm{kg} / \mathrm{m}^{3}\right)$ & Brita $\left(\mathrm{kg} / \mathrm{m}^{3}\right)$ & Água $\left(\mathrm{l} / \mathrm{m}^{3}\right)$ \\
\hline 476,74 & 607,66 & 1170,92 & 205 \\
\hline
\end{tabular}


No total foram produzidos 66 corpos de prova, divididos em 11 lotes, com 6 corpos de prova cada, e identificados por siglas que referenciam o número de dias e a temperatura de cura, conforme apresentado na Tabela 2. Devido à capacidade de produção da betoneira os corpos de prova foram moldados em duas etapas.

Previamente ao ensaio de compressão as faces dos corpos de prova foram retificadas. Os ensaios de resistência à compressão axial (FIGURA 2) foram realizados em uma máquina universal de ensaios, com capacidade de carga de $2000 \mathrm{kN}$, seguindo as recomendações da NBR 5739 (ABNT, 2007), nas idades de 3, 7 e 28 dias.
A resistência à compressão uniaxial foi comparada entre concretos submetidos às duas condições de cura para as três idades de ensaio. Além disso, foi avaliada a evolução da resistência do concreto quando submetido à cura em baixa temperatura nas primeiras idades e posteriormente em temperatura ambiente. Para a idade de 7 dias um lote de corpos de prova foi submetido à cura em baixa temperatura durante os 3 primeiros dias e em temperatura ambiente nos 4 dias finais e para a idade de 28 dias dois lotes tiveram alternância de tratamento, sendo 3 dias frio e 25 ambiente (3F25A) e 7 dias frio e 21 ambiente (7F21A).

\begin{tabular}{ccc}
\multicolumn{3}{c}{ TABELA 2: Siglas de identificação dos lotes de corpos de prova. } \\
Sigla & $\begin{array}{c}\text { Tempo de cura a } 5{ }^{\circ} \mathrm{C} \\
\text { (dias) }\end{array}$ & $\begin{array}{c}\text { Tempo de cura a } 23 \pm 2{ }^{\circ} \mathrm{C} \\
\text { (dias) }\end{array}$ \\
\hline $3 \mathrm{~F}$ & 3 & 0 \\
\hline $3 \mathrm{~A}$ & 0 & 3 \\
\hline $3 \mathrm{~F} 4 \mathrm{~A}$ & 3 & 4 \\
\hline $3 \mathrm{~F} 25 \mathrm{~A}$ & 3 & 25 \\
\hline $7 \mathrm{~F}$ & 7 & 0 \\
\hline $7 \mathrm{~A}$ & 0 & 7 \\
\hline $7 \mathrm{~F} 21 \mathrm{~A}$ & 7 & 21 \\
\hline $28 \mathrm{~F}$ & 28 & 0 \\
\hline $28 \mathrm{~A}$ & 0 & 28 \\
\hline
\end{tabular}

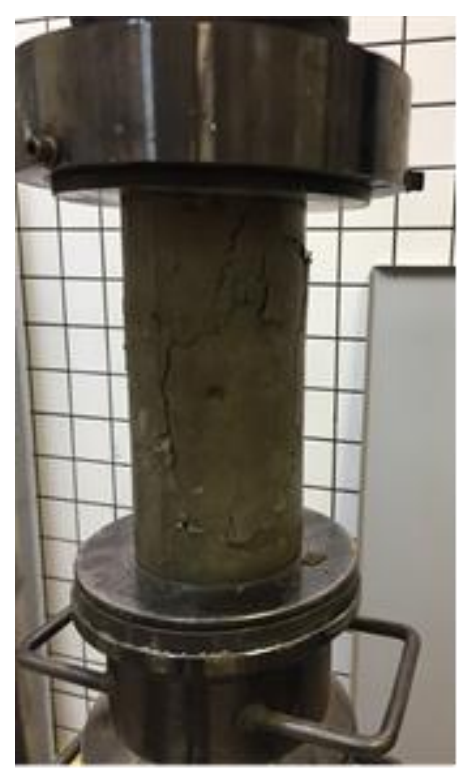

FIGURA 2: Corpo de prova submetido ao ensaio de resistência à compressão axial. 


\section{RESULTADOS E DISCUSSÕES}

Nas Tabelas 3 e 4 são apresentados os resultados de resistência à compressão uniaxial obtidos para os corpos de prova das betonadas $1 \mathrm{e}$ 2 , respectivamente, para cada condição de cura e idade de ensaio. Visto que alguns lotes produzidos em betonadas diferentes foram ensaiados na mesma idade, os tratamentos iguais foram identificados com um número sobrescrito que corresponde ao número da betonada.
Analisando as resistências médias dos tratamentos verifica-se que aos sete dias os corpos de prova apresentaram resistência acima de $50 \%$ do valor obtido aos 28 dias, independente da temperatura de cura, alcançando na idade final, valores próximos a $40 \mathrm{MPa}$. Entre as duas betonadas verificou-se uma variação de aproximadamente $5 \%$ na resistência à compressão dos corpos de prova curados em água à temperatura próxima de $23^{\circ} \mathrm{C} \mathrm{e}$ ensaiados aos 28 dias.

TABELA 3: Resistência à compressão axial dos corpos de prova da betonada 1 (MPa).

\begin{tabular}{ccccccc}
$\begin{array}{c}\text { Tratamento } \\
\text { Corpo de prova }\end{array}$ & $3 F$ & $3 A$ & $3 F 4 A$ & $3 A^{1}$ & $3 F 25 A$ & $28 A^{1}$ \\
\hline 1 & 24,62 & 29,67 & 35,6 & 32,7 & 42,77 & 42,94 \\
\hline 2 & 21,59 & 25,83 & 32,7 & 31,71 & 43,38 & 35,59 \\
\hline 3 & 24,33 & 28,41 & 34,81 & 31,55 & 45,66 & 44,12 \\
\hline 4 & 23,07 & 29,54 & 33,27 & 35,44 & 47,33 & 40,90 \\
\hline 5 & 22,85 & 26,58 & 32,92 & 31,61 & 45,27 & 41,48 \\
\hline 6 & 23,60 & 26,23 & 36,91 & 34,29 & 41,45 & 37,96 \\
\hline Média & 23,34 & 27,71 & 34,37 & 32,88 & 44,31 & 40,50 \\
\hline Desvio padrão & 1,10 & 1,71 & 1,69 & 1,63 & 2,16 & 3,19 \\
\hline
\end{tabular}

TABELA 4: Resistência à compressão axial dos corpos de prova da betonada 2 (MPa).

\begin{tabular}{cccccc}
\hline $\begin{array}{c}\text { Tratamento } \\
\text { Corpo de prova }\end{array}$ & $7 \mathrm{~F}$ & $7 \mathrm{~A}^{2}$ & $7 \mathrm{~F} 21 \mathrm{~A}$ & $28 \mathrm{~F}$ & $28 \mathrm{~A}^{2}$ \\
\hline 1 & 29,07 & 33,88 & 41,64 & 41,19 & 44,64 \\
\hline 2 & 24,47 & 34,80 & 42,14 & 39,70 & 43,14 \\
\hline 3 & 28,58 & 35,47 & 44,71 & 35,96 & 43,07 \\
\hline 4 & 29,36 & 33,16 & 49,16 & 35,89 & 42,89 \\
\hline 5 & 27,26 & 37,15 & 40,96 & 37,30 & 38,85 \\
\hline 6 & 28,17 & 34,99 & 46,08 & 41,46 & 43,46 \\
\hline Média & 27,82 & 34,91 & 44,12 & 38,58 & 42,68 \\
\hline Desvio padrão & 1,80 & 1,38 & 3,15 & 2,53 & 1,98 \\
\hline
\end{tabular}




\subsection{EFEITO DA TEMPERATIRA DE CURA NA RESISTÊNCIA À COMPRESSÃO}

Na Figura 3 são apresentadas a resistência média à compressão e o desvio padrão de cada lote, demonstrando a evolução da resistência ao longo do tempo de cura. Os corpos de prova curados em água à temperatura ambiente apresentaram resistência superior aos curados em baixa temperatura. É interessante destacar que a resistência obtida pelo concreto em sete dias de exposição ao frio foi minimamente superior à resistência aos três dias do concreto que curado em a temperatura ambiente. Tal fato demonstra que, em termos gerais, sob condições de baixa temperatura o concreto requer, para atingir a resistência esperada aos 3 dias, mais do que o dobro do tempo.

$\mathrm{Na}$ idade de três dias verifica-se que os corpos de prova submetidos ao processo de cura a $5^{\circ} \mathrm{C}$ (3F) apresentaram resistência à compressão média 15,7\% inferior em comparação aos corpos de prova curados em temperatura próxima a $23{ }^{\circ} \mathrm{C}$ (3A). Para a idade de sete dias, o concreto que teve seu processo de cura em $5^{\circ} \mathrm{C}$ (7F) apresentou resistência à compressão $20 \%$ inferior às amostras curadas em temperatura ambiente $\left(7 A^{1}\right)$. Entretanto, para o lote que permaneceu 28 dias de cura exposto ao frio $(28 \mathrm{~F})$ a resistência apresentou resultado somente $4,73 \%$ inferior à resistência desenvolvida pelo concreto que teve toda sua cura em temperatura ambiente $\left(28 \mathrm{~A}^{2}\right)$.

Para avaliar a igualdade dos resultados obtidos nas duas condições de temperatura de cura foi realizado o teste $\mathrm{t}$-Student, utilizando o programa $R$, para as idades de 3, 7 e 28 dias, com intervalo de confiança de $95 \%$, sendo os resultados apresentados na Tabela 5.

As médias das resistências à compressão demonstram que a cura do concreto em baixa temperatura influencia nesta propriedade mecânica, sendo comprovada a diferença estatística entre os dois tratamentos, por apresentar $\mathrm{p}$-valor inferior a 0,05.

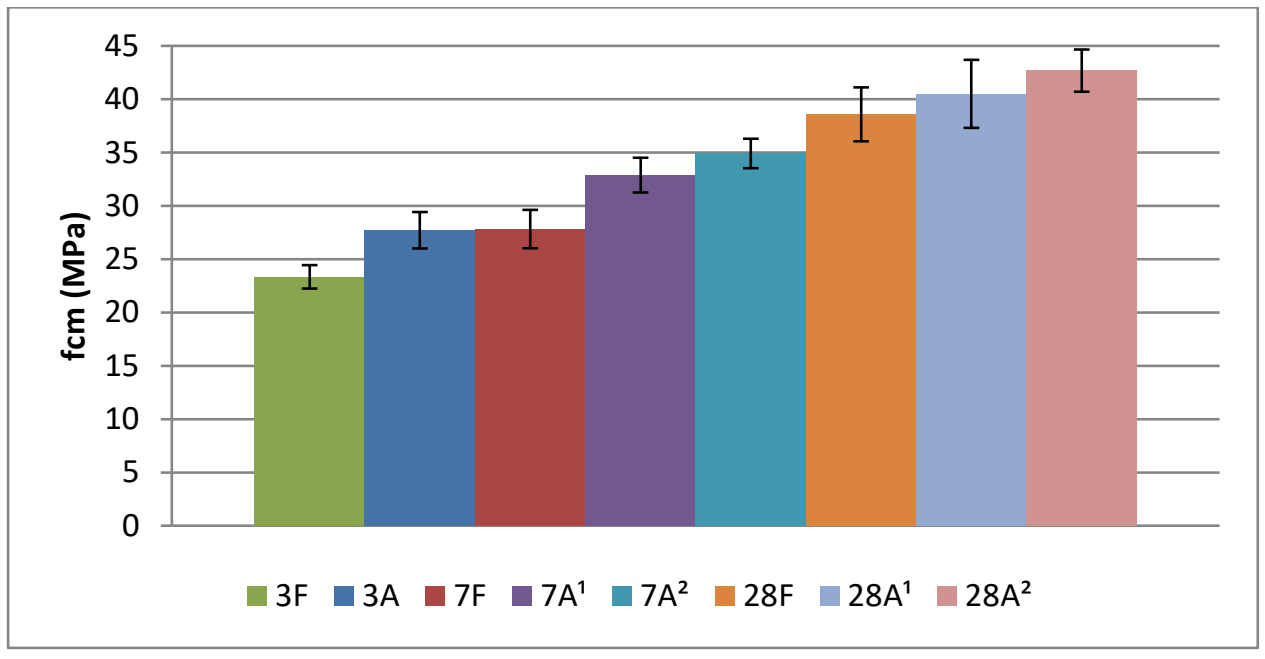

FIGURA 3: Resistência à compressão média e desvio padrão dos corpos de prova ensaiados.

TABELA 5: Resultados do teste de comparação $t$-Student.

\begin{tabular}{ccc} 
Tratamento & $\begin{array}{c}\text { Resistência Média } \\
(\mathrm{MPa})\end{array}$ & p-valor \\
\hline $3 \mathrm{~F}$ & 23,34 & \multirow{2}{*}{0,0003} \\
\hline $3 \mathrm{~A}$ & 27,71 & \multirow{2}{*}{0,0001} \\
\hline $7 \mathrm{~F}$ & 27,82 & \\
\hline $7 \mathrm{~A}$ & 34,91 & \multirow{2}{*}{0,0108} \\
\hline $28 \mathrm{~F}$ & 38,58 & \\
\hline $28 \mathrm{~A}$ & 42,68 &
\end{tabular}




\subsection{EVOLUÇÃO DA RESISTÊNCIA PÓS-BAIXA TEMPERATURA}

Para avaliar o aumento de resistência do concreto pós-baixa temperatura dois lotes de corpos de prova foram curados em $5{ }^{\circ} \mathrm{C}$ durante os 3 primeiros dias e depois transferidos para cura em água à temperatura ambiente durante 4 dias (3F4A) e 25 dias (3F25A), sendo rompidos aos 7 e 28 dias, respectivamente, e comparados com os corpos de prova submetidos somente à cura em temperatura durante a mesma idade (28A $\left.\mathrm{A}^{1}\right)$.

$\mathrm{Na}$ Figura 4 são apresentadas as resistências médias à compressão dos corpos de prova curados em temperatura ambiente e aqueles com cura em temperaturas alternadas. Aos sete dias de idade verificou-se que os corpos de prova, submetidos incialmente ao frio, apresentaram resistência $4,5 \%$ superior àqueles curados sete dias em temperatura ambiente. Resultado semelhante foi observado aos 28 dias, quando os corpos de prova curados inicialmente no frio apresentaram resistência 9,4\% superior aos corpos de prova curados em água à temperatura ambiente.

$\mathrm{Na}$ Tabela 6 são apresentados os resultados do teste de comparação t-Student para resistência à compressão dos tratamentos dos corpos de prova com alternância do processo de cura e aqueles submetidos somente à cura em temperatura ambiente.

A partir da análise estatística conclui-se que a exposição do concreto à baixas temperaturas durante os 3 primeiros dias não influenciou significativamente na resistência obtida aos 7 dias, entretanto quando comparados os dois tratamentos para resistência obtida aos 28 dias foi constatada variação significativa nos resultados, podendo ser considerados diferentes.

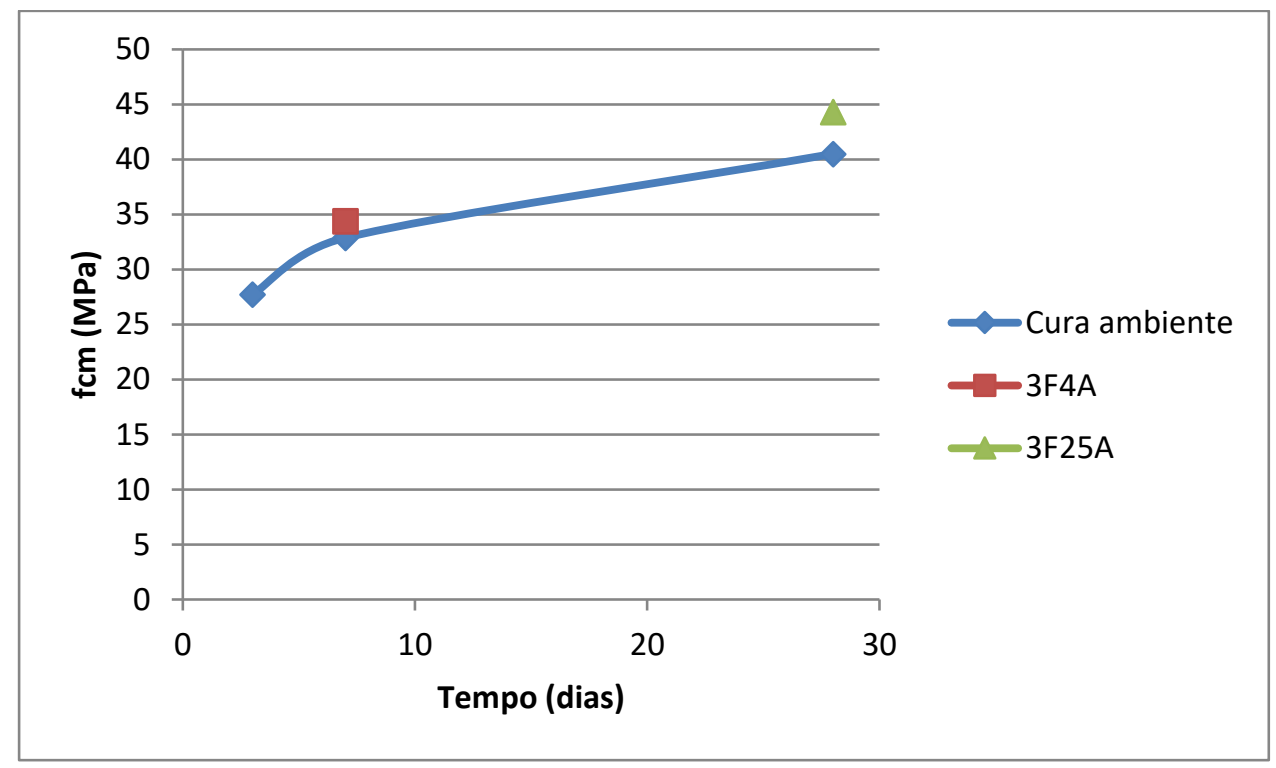

FIGURA 4: Resistência à compressão média dos corpos de prova curados condições de temperatura alternadas.

TABELA 6: Resultados do teste de comparação t-Student.

\begin{tabular}{ccc} 
Tratamento & $\begin{array}{c}\text { Resistência Média } \\
\text { (MPa) }\end{array}$ & p-valor \\
\hline 3F4A & 34,37 & 0,1525 \\
\hline $7 A$ & 32,88 & \multirow{2}{*}{0,0388} \\
\hline $3 F 25 A$ & 44,31 & \\
\hline $28 A$ & 40,50 &
\end{tabular}


Segundo Cecconello e Tutikian (2012), quanto mais lenta for a hidratação do cimento Portland, melhor será a estrutura cristalina do concreto. Desta forma, é justificável que os elementos que foram expostos, em suas idades iniciais à baixa temperatura apresentem um desempenho superior ao de elementos curados em temperatura ambiente. Verifica-se, portanto, que temperaturas na faixa de $5^{\circ} \mathrm{C}$ são capazes de desacelerar o processo de hidratação do cimento.

Helene e Terzian (1993), ao analisar profundamente a hidratação dos compostos químicos presentes no cimento, verificaram que a resistência à compressão em idades iniciais depende da hidratação de compostos como o aluminato tricálcico (C3A) e o ferro-aluminato (C4AF), que são responsáveis pelo enrijecimento da pasta de cimento (formação de etringitas e posteriormente dão origem a monossulfatos hidratados) enquanto em idades mais avançadas prevalece a influência da hidratação dos silicatos bicálcicos (C2S), responsável pela resistência da pasta endurecida.

Na Figura 5 são apresentadas a resistência média e o desvio padrão dos corpos de prova curados em baixa temperatura durante os 7 primeiros dias e posteriormente em temperatura ambiente (7F21A) e dos corpos de prova curados durante 28 dias em baixa temperatura e em temperatura ambiente. Os corpos de prova do tratamento 7F21A apresentaram resistência 3,3\% superior aos corpos de prova curados somente em temperatura ambiente $\left(28 \mathrm{~A}^{2}\right)$ e $14,3 \%$ superior aos corpos de prova curados somente em baixa temperatura (28F). Constata-se assim que a exposição à temperatura de $5^{\circ} \mathrm{C}$ afetou de forma mais acentuada o desenvolvimento da resistência em idades iniciais, e que ao transferir o material para as condições de temperatura ambiente, o concreto foi capaz de obter uma resistência final superior aos concretos curados durante os 28 dias em temperatura ambiente ou em baixa temperatura.

A análise estatística dos tratamentos 7F21A, 28A $\mathrm{A}^{2}$ e $28 \mathrm{~F}$ foi realizada utilizando a análise de variância (ANOVA) (Tabela 7) e teste de Tukey para comparação das médias (Tabela 8), com intervalo de confiança de $95 \%$.

A partir dos resultados da análise estatística conclui-se que entre os tratamentos $7 F 21 \mathrm{~A}$ com $28 \mathrm{~F}$ e $28 \mathrm{~A}^{2}$ com $28 \mathrm{~F}$ as resistências à compressão aos 28 dias são diferentes, de forma que a cura em baixa temperatura apresentou melhora nesta propriedade do concreto. Entretanto, o tempo de exposição ao frio não influenciou significativamente a resistência à compressão, visto que os resultados dos tratamentos $7 F 21 \mathrm{~A}$ e $28 \mathrm{~A}^{2}$ podem ser considerados estatisticamente iguais.

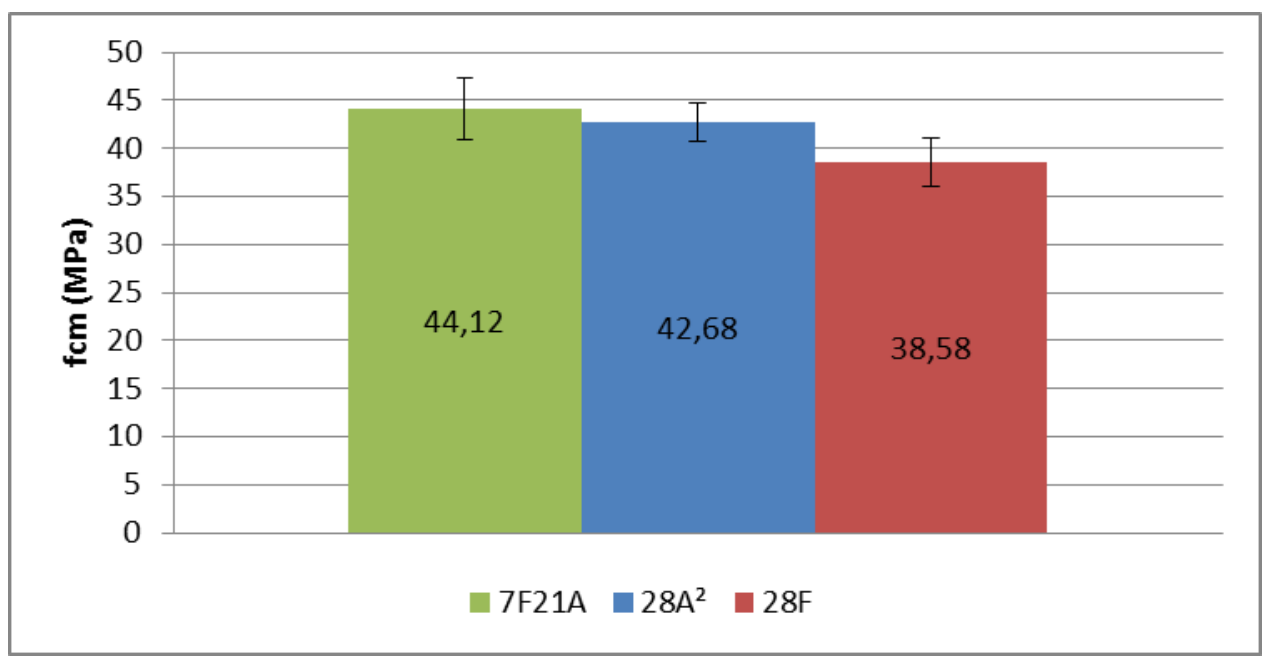

FIGURA 5: Resistência à compressão média e desvio padrão dos corpos de prova ensaiados em 28 dias. 
TABELA 7: Resultados da Análise de Variância.

\begin{tabular}{ccccccc}
\hline Grupo & Contagem & Soma & Média & Variância & & \\
7F21A & 6 & 264,69 & 44,12 & 9,93 & & \\
$28 \mathrm{~A}^{2}$ & 6 & 256,05 & 42,68 & 3,91 & & \\
28F & 6 & 231,50 & 38,58 & 6,42 & & \\
\hline \hline Fonte da variação & $S Q$ & $g l$ & $M Q$ & $F$ & valor-P & F crítico \\
\hline Entre grupos & 98,83 & 2 & 49,42 & 7,319 & 0,006 & 3,682 \\
Dentro dos grupos & 101,27 & 15 & 6,75 & & & \\
Total & 200,10 & 17 & & & & \\
\hline
\end{tabular}

\begin{tabular}{|c|c|c|c|}
\hline Comparação & Diferença entre médias & Diferença significativa & Conclusão \\
\hline $7 F 21 A \times 28 A^{2}$ & 1,440 & 3,893 & Médias iguais \\
\hline $7 F 21 A \times 28 F$ & 5,532 & 3,893 & Médias diferentes \\
\hline $28 A^{2} \times 28 F$ & 4,092 & 3,893 & Médias diferentes \\
\hline
\end{tabular}

\section{CONCLUSÕES}

Os resultados obtidos no programa experimental evidenciaram que a exposição do concreto em condições de baixas temperaturas pode influenciar negativamente o desenvolvimento inicial da resistência à compressão do material.

Concretos submetidos à temperatura de $5^{\circ} \mathrm{C}$ durante 3,7 e 28 dias apresentaram redução da resistência em relação à concretos submetidos à temperatura ambiente.

Apesar de reduzir a velocidade de aumento da resistência à compressão do concreto, a cura em temperatura de $5^{\circ} \mathrm{C}$ durante os primeiros dias combinada com a cura ambiente, resultou em resistência aos 28 dias superior ao concreto curado somente em temperatura ambiente, atribuída à redução da velocidade de hidratação do concreto, melhorando este processo. A cura em baixa temperatura durante os 3 primeiros dias resultou em maior resistência final do concreto em relação ao mesmo processo durante 7 dias.

Aplicando os resultados obtidos na prática da construção civil conclui-se que cuidados especiais devem ser tomados para concretagens em dias com temperaturas próximas a $5^{\circ} \mathrm{C}$, principalmente quanto ao tempo de desforma dos elementos estruturais de concreto.

\section{REFERÊNCIAS BIBLIOGRÁFICAS}

ASSOCIAÇÃO BRASILEIRA DE NORMAS TÉCNICAS. NBR 5738: Concreto - Procedimento para moldagem e cura de corpos de prova. Rio de Janeiro, 2015.

NBR 5739: Ensaio de compressão de corpos-deprova cilíndricos. Rio de Janeiro, 2007.

NBR 14931: Execução de estruturas de concreto

- Procedimento. Rio de Janeiro, 2004.

NBR NM 67: Concreto: Determinação da consistência pelo abatimento do tronco de cone. Rio de Janeiro, 1998.

CECCONELLO, V., TUTIKIAN, B. The influence of low temperature on the evolution of concrete strength. Revista Ibracon de Estruturas e Materiais, V5, $n^{\circ} 1$, São Paulo, Feb 2012.

HELENE, P. R. L., TERZIAN, P. Manual de dosagem e controle do concreto. São Paulo, Pini, 1993. 349 p.

INMET - Instituto Nacional de Meteorologia. Temperatura média anual. Brasília - DF. Disponível em: $<$

http://www.inmet.gov.br/portal/index.php?r=clima/pag e\&page =anomaliaTempMediaAnual> Acesso em: 30 abr. 2017.

KOSMATKA, S. H., KERKHOFF, B., PANARESE, W. C. Design and control of concrete mixtures. 14th ed. Skokie, Illinois, USA: Portland Cement Association; 2003. pp. 358.

KRYLOV, B.A. Cold weather concreting. Book review. J of Cold Reg Eng 1999:213-4 
LANSINI, B. Influência da temperatura de cura na resistência à compressão do concreto. TCC (Graduação em Engenharia Civil) - Universidade Federal do Rio Grande do Sul, Porto Alegre, 2016, 76 p.

MEHTA, P. K.; MONTEIRO, P. J. M. Concreto Microestrutura, Propriedade e Materiais. 3a edição. Ed.:IBRACON. 2008, p. 674

NASSIF, A., PETROU, M. F. Influence of cold weather during casting and curing on the stiffness and strength of concrete. Construction and Building Materials, 44, 2013, 161-167.

NERY, J. T. Dinâmica climática da região sul do brasil. Revista Brasileira de Climatologia. V1, n 1. Aracaju, SE. 2005.

OLIVEIRA, R. M. Relação entre distribuição de espécies arbóreas em matas úmidas e os fatores ambientais da costa atlântica brasileira. Tese (Doutorado em Geociências) - Universidade Estadual Paulista, Instituto de Geociências e Ciências Exatas - Rio Claro, 2003, 212 p.

ORTIZ, J., AGUADO, A., AGULLÓ, L., GARCIA, T. Influence of environmental temperatures on the concrete compressive strength: Simulatio of hot and cold weather conditions. Cement and Concrete Research. 35, 2005, 1970-1979.

REGINATO, L. A., FOIATO, M., PIOVESAN A. Z. Avaliação da resistência à compressão do concreto curado em baixa temperatura. UNOESC \& Ciência ACET. V.4, n.2 (2013). 